\title{
The State of Disease-Related Awareness Regarding Cutaneous Leishmaniasis Cases in Sanliurfa, Delay Level in Treatment and Reasons for Delay
}

Ibrahim KORUK, Burcu BEYAZGUL, Sule ALLAHVERDI*, Rüstem KUZAN

Harran University Faculty of Medicine, Department of Public Health, Sanliurfa, 63300, Turkey

DOI: $10.36348 / \mathrm{sjm} .2020 . v 05 i 09.002$

| Received: 28.08.2020 | Accepted: 05.09.2020 | Published: 09.09.2020

*Corresponding Author: Sule Allahverdi

\section{Abstract}

Purpose: The research was conducted to determine the knowledge level, awareness status, delay level in treatment and causes of delay of the cases of cutaneous leishmaniasis in Sanliurfa province. Method: The research is a cross-sectional study. It was conducted between November-December 2018. The patients who applied to Sanliurfa Cutaneous Leishmaniasis Diagnosis and Treatment Center (SCLDTC) constitute the study population. 375 people participated in the study. Findings: The median age of the participants was 17 years (mean $22.1 \pm 17.9$ ) and 50.9\% were under 18 years of age. $53.3 \%$ of the patients were female and $46.7 \%$ were male. The education level of $51.7 \%$ of adult participants and the mothers of participants under the age of 18 was below the primary school. 54.9\% of the participants or their families did not work in any job. $45.3 \%$ of the patients had facial lesions. A delay was found in $41.4 \%$ of patients although they directly applied to SCLDTC and 58.6\% of them who applied to SCLDTC after referral. 344 of CL patients experienced a total of 570 delays in different stages of access to treatment. $32.8 \%$ of those who had access to CLDTC after direct application or referral had patient delay. The most common patient delay causes are assuming that it is acne with $16.5 \%$ and neglecting with $14.6 \%$. Delays due to health care centers are mostly in public hospitals at $13.2 \%$. $91.6 \%$ of delays are due to dermatology clinics. The reason for the delay is that misdiagnosis and the wrong treatment in dermatology clinics. $49.6 \%$ of the delay cases were caused by the CLDTC and the most common reason for the delay was the absence of medication with $48.4 \%$. In the logistic regression model, where independent variables affecting the patient delay are evaluated together, that the lesion is on the face increases early treatment application 2.4 times and that having only one lesion increases it 1.8 times. Result: Patients' level of basic education and knowledge of the disease is low. Although the patients knew that they should apply directly to the CLDTC, patient delay levels are high. The presence of lesions in regions other than the face decreases patients' behavior of seeking early treatment. Therefore, the information and awareness of the patients and the society about CL should be increased, the patients applying to CLDTC and their relatives should be informed, these training should be pursued and supported by posters and brochures in women's support centers, schools, etc. Compliance training should be performed with appropriate time intervals in CLDTC, with dermatologist physicians, who will work in Sanliurfa in order to reduce system delays. Pentavalent antimony required for the CLDTC and other centers should be provided on time.

Keywords: Cutaneous leishmaniasis, treatment-seeking behavior, delay in treatment.

Copyright @ 2020: This is an open-access article distributed under the terms of the Creative Commons Attribution license which permits unrestricted use, distribution, and reproduction in any medium for non-commercial use (NonCommercial, or CC-BY-NC) provided the original author and source are credited.

\section{INTRODUCTION}

Leishmaniasis is a protozoal disease transmitted by the bite of infected female midges. About 12 million people in 98 countries worldwide have leishmaniasis and 350 million people are reported to be at risk. It is estimated that 2 million new cases are added to these patients each year, and approximately 1.5 million of these cases are of cutaneous leishmaniasis (CL) type [1,2].
Between 2008 and 2017, the number of CL cases ranged from 1113 to 2460 (with a morbidity rate of 1.58-3.04 per hundred thousand) in Turkey. It has been observed that since 2016, morbidity has started to decrease but that it has remained as 3 in a hundred thousand for the last three years [3]. In Turkey, Southeastern Anatolia and Çukurova region are endemic regions in terms of CL. More than half of the CL cases determined in Turkey between the years 19902010 were detected in Sanliurfa [4]. Although the disease does not show a significant increase, it is noteworthy that it cannot be brought under control 
despite the knowledge of its etiology and the existence of its effective diagnosis and treatment [5]. While CL usually causes ulcerated lesions on open parts of the body such as the face, arms, and legs, when ulcers heal, they leave serious permanent marks [6, 7]. These scars can cause stigmatization and significant psycho-social problems, which can reduce the quality of life [8]. However, approximately $15 \%$ of CL patients may have a more severe condition and therefore require longer and more frequent treatment $[1,9]$. Although CL is not fatal, delayed diagnosis and treatment increase the risk of contamination and morbidity of the disease [8]. Therefore, in the prevention of the disease, it is very important to treat patients at an early stage and to reduce the resorvoirs [10]. However, there are many factors that determine treatment-seeking behavior and that delay treatment. Some of these releated patients and some from the health institutions or health personnel [11]. Most of the patients never apply to health care centers for diagnosis and treatment or may apply late for reasons such as the disease's not being paid enough attention or being accepted by the society $[1,9]$. Although there is no clear definition of delay time, there are researches that define the time spent by individuals from the moment they notice the disease until they apply to the health institution as patient delay $[8,12]$. On the other hand, missing patient refferals between the steps in the diagnosis process may delay access to treatment centers. Patient and system induced delays are together cause on total treatment delay [7, 13]. However, the success of preventive measures also depends on the knowledge, attitude, and behaviors of the people at risk. It is necessary to know at which stages and levels that the risk factors in the society and system delays are realized to control CL disease [14, $15]$.

The aim of this study was to determine the knowledge level, awareness, treatment delay status and the causes of treatment delay in the cases of CL in Sanliurfa province.

\section{MATERIAL AND METHOD \\ The Research Was Cross-Sectional}

The population of the study consists of patients diagnosed with CL in Sanliurfa. Approximately $91.0 \%$ of patients are in central districts, and $9.0 \%$ are in other districts.

While local CL treatment in Sanliurfa was conducted in Bozova, Akçakale, Ceylanpınar, Suruç, Birecik, Harran, Viranşehir districts by the District Health Directorate of Infectious Diseases Unit and Sanliurfa Cutaneous Leishmaniasis Diagnosis and Treatment Center (CLDTC), affiliated to the Public Health Services Directorate, Infectious Diseases Unit in the central district, the systemic treatment is performed by Harran University Faculty of Medicine, Department of Dermatology. The CLDTC in the city center is the main center for treating $91.0 \%$ of the cases diagnosed in
Sanliurfa. Patients or those who suspect that they may have an CL may both apply to CLDTC or District Health Directorate of Infectious Diseases Unit directly and be referred by the health care centers. In fact, it is desirable and encouraged for people who are suspected of CL to go directly to this treatment centers.

A pilot study was conducted with 42 CL cases admitted to CLDTC to determine estimated treatment proportion. The sample size was calculated as 375 patients with an $42.0 \%$ estimated treatment delay proportion in $95.0 \%$ confidence level and $5.0 \%$ of marjin of error.

Data were started to be collected in November and no one refused to participate in the study. Stratification was made according to the number of patients in the districts and 341 people were included from central districts, 34 from other districts. The research was conducted with the ethical approval of Harran University, Faculty of Medicine, Ethics Committee (session dated 05.11.2018 and numbered 11) and written permission from Sanliurfa Provincial Health Directorate. The purpose of the study was explaned and informed consent was obtained from participants.

As the data collection tool, "Information Status, Disease Awareness Status and Access to Health Services Form of CL Cases in Sanliurfa" were used. This form consists of 4 sections. In the first part, there are 2 questions about the number of lesions and their location. In the second part, there are 6 questions that question the characteristics of the patients such as age, educational status, working in a job, migratory seasonal farmwork (MSF) status of the family, animal feeding near the house and dog feeding at home. In the third part, there are 4 questions aimed at measuring the knowledge and awareness of the patients such as contamination, prevention, complications due to nontreatment, and the state of having CL in relative/neighbors. In the fourth part, a Delay Stages Scheme was established to determine the steps of patients' state of experiencing a delay in the treatment of CL. This scheme was designed in four stages, considering the individual behaviors and the steps in the health system.

In the first stage, the state of patient delay is questioned. If there was a delay, its cause and duration were asked.

In the second stage, delays caused by primary health care centers (family health center; FHC) are questioned. If there was a delay, its cause and duration were asked.

In the third stage, delays due to secondary and tertiary health care centers (public hospitals, private hospitals, university hospitals) were questioned. If there was a delay, its cause and duration were asked. 
In the fourth stage, the state of delay caused by the CLDTC was questioned. If there was a delay, its cause and duration were asked.

The delays in the second, third and fourth stages were defined as system delays. It was assumed that each patient may experience a delay in different and multiple stages.

The questionnaire was applied to every patient who applied to and CL diagnosed by the Cutaneous Leishmaniasis Diagnosis and Treatment Center. The researchers filled in the questionnaire by face to face interviews. Each interview lasted approximately 15 minutes. For patients younger than 18 years, the interview was conducted with an adult accompanying the patient.

The dependent variable of the study are treatment delay status, causes of treatment delay, patient delay status of the CL cases.

Independent variables were only formed for patient delay. These are the location of the lesion, the number of the lesions, the patient's age, educational status, employment status, the migratory seasonal farmworker status of the family, the status of information and awareness about CL.

Considering delay in the treatment of CL, the disease's response to the treatment and the response period and changes determined in the immunohistochemical studies, initiation of the treatment 3 months after the appearance of the lesion and afterward was identified as delay [16].

Regarding educational status, for those under 18 years of age, the mother's educational status was included.

Regarding employment status, the father's employment status was included for those under 18 years of age.

In data analysis, descriptive statistics were used and the Chi-square test was used for univariate analysis.

The logistic regression model was formed with the variables of employment status (categorical), lesion location (categorical), number of lesions (categorical) and age (categorical), which were make the differences in univariate analysis. The analyses were performed using IBM SPSS 20.0 Statistical Package Program.

\section{FINDINGS}

The median age of the participants was 17 years (mean $22.1 \pm 17.9$ ) and $50.9 \%$ were under 18 years of age. $53.3 \%$ of the patients were female and $46.7 \%$ were male. The education level of $51.7 \%$ of the mothers of adult participants and participants under the age of 18 was below the primary school.

$54.9 \%$ of the participants or their families were unemployed and $25.6 \%$ of them performed MSF (Table-1). $41.6 \%$ of the participants had animal shelters near their houses and $8.3 \%$ of them kept dogs at home.

$91.0 \%$ of the patients live in the city center. $41.9 \%$ of the patients had 1 or more lesions. $45.3 \%$ of the patients had facial lesions (Table-1). Whereas single lesions were more common in the facial region with $51.8 \%$, multiple lesions were more common in the other regions with $78.4 \%$.

Considering the state of knowledge and awareness, the state of knowing the contamination of the disease is $53.6 \%$, knowing the preventability is $27.7 \%$, and knowing the harmfulness is $82.4 \%$. $70.9 \%$ of the participants had a history of the disease in their families and/or neighbors. The effect of knowledge and awareness status characteristics on patient delay state was not shown (Table-2).

Only $41.4 \%$ of CL patients applied directly to CLDTC, while others were able to reach it after a referral from different health care centers. A delay was found in $35.5 \%$ of patients although they directly applied to CLDTC and $56.2 \%$ of them who applied to CLDTC after referral. Overall, $91.7 \%$ of patients were found to have delayed treatment. It was found that, regarding the direct applications to CLDTC, the most common treatment delay was based on CLDTC with $29,6 \%$. It was determined that post-referral delays occurred at more than two different stages at a level of $37.2 \%$ (Table-3).

344 of CL patients experienced a total of 570 delays in different stages of access to treatment. $32.8 \%$ of those who had access to CLDTC after direct application or referral had patient delay. The most common individual causes are assuming that it is acne with $16.5 \%$ and neglecting with $14.6 \%$. Delays due to health care centers are mostly in public hospitals at $13.2 \% .91 .6 \%$ of delays are due to dermatology clinics. The reason for the delay is that misdiagnosis and the wrong treatment (Table-4). $49.6 \%$ of the treatment delay cases were caused by the CLDTC and the most common reason for the delay was the absence of medication with $48.4 \%$ (Table-4).

The mean delay duration due to patient is $4.8 \pm$ 2.6 months; the mean delay duration due to ASM and hospitals is $1.9 \pm 3.0$ months and the mean delay duration due to CLDTC is $2.4 \pm 1.3$ months. The mean delay duration due to the health system (FHC, state/private hospital, university hospital, CLDTC) is $2.3 \pm 1.9$ months. 
When the effect of socio-demographic and lesion characteristics on the presence of patient delay was examined, patient delay was found to be higher in those whose father was unemployed compared to those who were employed, those who had no lesion on their faces compared to those who had a lesion, who had 2 or more lesions compared to those who had 1 or less lesion, and those who were 18 years old and older compared to those who were under 18 years of age $(\mathrm{p}<0.05)$. Gender, educational status, social class, MSF status, presence of animal shelter near home, and the state of dog feeding at home were not found to have any effect on the state of patient delay (Table-5).

In the logistic regression model, where independent variables affecting patient delay were evaluated together, the presence of lesion in regions other than the face increases patient delay 2.4 times and that the number of lesions is 2 and above increases patient delay 1.8 times (Table-5).

Table-1: Distribution of lesion characteristics and some socio-demographic characteristics of patients according to patient delay

\begin{tabular}{|l|l|l|l|l|l|l|l|}
\hline & \multicolumn{6}{|l}{ Patient delay Status } \\
\hline & Present & $\mathbf{\%}^{*}$ & None & $\mathbf{\%}^{*}$ & $\mathbf{\%} *$ & $\chi^{2}$ & P \\
\hline Age & & & & & & & \\
\hline$<18$ & 83 & 43.5 & 108 & 56.5 & 50.9 & 5.88 & $\mathbf{0 . 0 1}$ \\
\hline$\geq 18$ & 104 & 56.5 & 80 & 43.5 & 49.1 & & \\
\hline Gender & & & & & & & \\
\hline Female & 103 & 51.5 & 97 & 48.5 & 53.3 & 0.32 & 0.56 \\
\hline Male & 84 & 48.0 & 91 & 52.0 & 46.7 & & \\
\hline State of Education & & & & & & & \\
\hline Couldn't Finish Primary School & 102 & 52.6 & 92 & 47.4 & 51.7 & 1.95 & 0.37 \\
\hline Primary and Secondary School & 55 & 44.7 & 68 & 55.3 & 32.8 & & \\
\hline High School and Above & 30 & 51.7 & 28 & 48.3 & 15.5 & & \\
\hline Employment status & & & & & & & \\
\hline Employed & 74 & 43.8 & 95 & 56.2 & 45.1 & 4.1 & $\mathbf{0 . 0 4 2}$ \\
\hline Unemployed & 113 & 54.9 & 93 & 45.1 & 54.9 & & \\
\hline MSF Status & & & & & & & \\
\hline Present & 55 & 57.3 & 41 & 42.7 & 25.6 & 2.46 & 0.11 \\
\hline No & 132 & 47.3 & 147 & 52.7 & 74.4 & & \\
\hline Lesion Location & & & & & & & \\
\hline On face region & 64 & 37.6 & 106 & 62.4 & 45.3 & 17.6 & $<\mathbf{0 . 0 0 0 1}$ \\
\hline Regions other than the face & 123 & 60.0 & 82 & 40.0 & 54.7 & & \\
\hline Number of Lesions & & & & & & & \\
\hline 1 & 95 & 43.6 & 123 & 56.4 & 58.1 & 7.64 & $\mathbf{0 . 0 0 6}$ \\
\hline$\geq 2$ & 65 & 41.4 & 92 & 58.6 & 41.9 & & \\
\hline Districts & & & & & & & \\
\hline City center & 171 & 50.1 & 170 & 49.9 & 90.9 & 0.27 & 0.870 \\
\hline District center & 16 & 47.1 & 18 & 52.9 & 9.1 & & \\
\hline Total & 187 & 49.9 & 188 & 50.1 & 100.0 & & \\
\hline
\end{tabular}

* Row percentage, $* *$ Column percentage

Table-2: Distribution of knowledge and awareness status of the patients regarding CL disease according to patient delay status

\begin{tabular}{|l|l|l|l|l|l|l|l|}
\hline & \multicolumn{2}{|l|}{ Patient delay Status } \\
\hline & Present & $\%^{*}$ & None & $\%^{*}$ & $\%^{* *}$ & $\chi^{2}$ & P \\
\hline Contamination Status & & & & & & & \\
\hline Knows & 95 & 47.3 & 106 & 52.7 & 53.6 & 0.96 & 0.32 \\
\hline Does not know & 92 & 52.9 & 82 & 47.1 & 46.4 & & \\
\hline Preventability & & & & & & & \\
\hline Knows & 46 & 44.2 & 58 & 55.8 & 27.7 & 1.53 & 0.21 \\
\hline Does not know & 141 & 52.0 & 130 & 48.0 & 72.3 & & \\
\hline Hazard Status & & & & & & & \\
\hline Knows & 149 & 48.2 & 160 & 51.8 & 82.4 & 1.54 & 0.21 \\
\hline Does not know & 38 & 57.6 & 28 & 42.4 & 17.6 & & \\
\hline Neighbor/Relative CL History & & & & & & & \\
\hline Present & 132 & 49.6 & 134 & 50.4 & 70.9 & 0.001 & 0.97 \\
\hline No & 55 & 50.5 & 54 & 49.5 & 29.1 & & \\
\hline Total & 187 & 100.0 & 188 & 100.0 & 100.0 & & \\
\hline
\end{tabular}


Table-3: Distribution of CL according to treatment delay status

\begin{tabular}{|l|l|l|}
\hline & $\mathrm{N}$ & $\%$ \\
\hline Direct Application to CLDTC & 155 & 41.4 \\
\hline No Delay & 22 & 5.9 \\
\hline Patient delay & 22 & 5.9 \\
\hline CLDTC induced delay & 57 & 15.2 \\
\hline Both patient and CLDTC based delay & 54 & 14.4 \\
\hline Application to CLDTC after referral & 220 & 58.6 \\
\hline No Delay & 9 & 2.4 \\
\hline 1 stage delay & 71 & 19.0 \\
\hline Delay in 2 different stages & 109 & 29.0 \\
\hline Delay in 3 different stages & 30 & 8.0 \\
\hline Delay in 4 different stages & 1 & 0.2 \\
\hline Total & 375 & 100.0 \\
\hline
\end{tabular}

Table-4: Distribution of treatment delays according to delay phase and cause of delay

\begin{tabular}{|l|l|l|l|}
\hline Delay phase & Cause of delay & $\mathbf{N}^{* *}$ & $\mathbf{\%}$ \\
\hline Individual & & 187 & 32.8 \\
\hline Application after referral & & & \\
\hline & Neglected & 49 & 8.6 \\
\hline & Assumed that it was acne & 54 & 9.5 \\
\hline & Assumed that it was a fly bite. & 8 & 1.4 \\
\hline Direct application to the CLDTC & & & \\
\hline & Neglected & 34 & 6.0 \\
\hline & Assumed that it was acne & 40 & 7.0 \\
\hline & Assumed that it was a fly bite. & 2 & 0.3 \\
\hline System based & & 100 & 17.6 \\
\hline FHC & Undiagnosed/incorrect medication & 17 & 3.0 \\
\hline Public Hospital & Undiagnosed/incorrect medication & 75 & 13.2 \\
\hline Private & Undiagnosed/incorrect medication & 6 & 1.1 \\
\hline Distribution according to clinics & & & \\
\hline & Dermatology & 77 & 91.6 \\
\hline & Internal medicine & 1 & 1.2 \\
\hline & Pediatrics & 2 & 2.4 \\
\hline & Ear Nose and Throat & 1 & 1.2 \\
\hline & Infectious Diseases & 0 & 0 \\
\hline & Emergency & 3 & 3.6 \\
\hline CLDTC induced delay & & 283 & 49.6 \\
\hline & No drugs & 276 & 48.4 \\
\hline & Pregnancy available & 3 & 0.7 \\
\hline & Undiagnosed & 570 & 100.0 \\
\hline & & & \\
\hline
\end{tabular}

* It shows a total of 84 applications to second and third level clinics.

** It was calculated over a total of 570 delays.

Table-5: Logistic regression model of factors affecting patient delay in the treatment of CL

\begin{tabular}{|l|l|l|l|l|l|}
\hline Variables & B & Standard deviation & P & O.R. & 95\% Confidence Interval \\
\hline Lesion region (other than the face) & 0.79 & 0.23 & 0.001 & 2.48 & 1.39 to 3.49 \\
\hline Number of lesions $(\geq 2)$ & 0.45 & 0.22 & 0.040 & 1.83 & $1: 02-2.43$ \\
\hline Employment status (unemployed) & 0.37 & 0.21 & 0.086 & 1.56 & $0.94-2.24$ \\
\hline Age ( $\geq 18)$ & 0.05 & 0.23 & 0.820 & 1.69 & $0.66-1.68$ \\
\hline Constant & -0.86 & 0.21 & $<0.0001$ & & \\
\hline
\end{tabular}

Makale “3.Uluslararas1-21.Ulusal Halk Sağlı̆̆ı Kongresi, 26-30 Kasım 2019, Antalya” adlı kongrede sözlü bildiri olarak sunulmuştur

\section{DISCUSSION}

The majority of CL patients in Sanliurfa are young people under the age of 18. Most of the patients' families are of low-income and a low level of education. More than half of the families do not work regularly and $1 / 4$ of them are migratory seasonal farmworkers. Similarly, in the study conducted in Bangladesh, $31.5 \%$ of the patients were under the age 
of $15,22.5 \%$ of the adults were under primary education, $14.0 \%$ were agricultural workers and $23.5 \%$ were not employed [12]. Again, in Bihar, India, 33.3\% of adult patients are found not to have finished primary education [8]. When evaluated together, it can be said that CL disease is seen mostly in the pediatric age group, individuals with low basic education and socioeconomic levels. Living with scarce resources, working in difficult and uncomfortable conditions, not benefiting sufficiently from health, education and social services seasonal farmworkers, like many other diseases in the world, are also at risk regarding CL [17]. Children are more likely to be involved in the patient group, probably because adults had these diseases in their childhood and developed immunity to them and children's immune systems are weaker [18].

There is an animal shelter near the houses of $41.6 \%$ of the patients and $8.3 \%$ of them feed dogs at home. In a study conducted in Çukurova, it was found that living near dog and animal shelters increased the risk of CL disease [19]. Although no finding has been obtained in this direction, this situation should be carefully monitored to create a habitat for carrier sand flies.

In Sanliurfa, the majority of CL patients have a low knowledge level about the infectiousness and preventability of the disease. Similarly, the level of knowledge on preventability was found to be low in the studies conducted in Syria (37.9\%) and Pakistan $(19.2 \%)$ [20, 21]. Low level of education can also be effective in the knowledge level's being so low. As a matter of fact, in the Iran study, the awareness of CL disease was found to be low in those with low education levels [22].

Although the level of knowledge about the disease in the patients in Sanliurfa is generally low, the level of information about the hazards of the disease is higher. In the study, the level of having CL in neighbors and relatives $(70.9 \%)$ was found to be higher than the Pakistan study (40.8\%) [20]. As a matter of fact, having correct information about the harmfulness of the disease may be related to the high rate of disease stories in neighbors and relatives. Similarly, in the Syria study, the presence of a disease history in close relatives significantly increases the knowledge level of the patient [21].

The main CL treatment in Sanliurfa is performed by the CLDTC located in the center of Sanliurfa. Only $8.3 \%$ of the patients who have reached the CLDTC by direct admission or referral can complete their treatment without delay. This result makes it important to identify the delay stages and the causes of delay.

When all delay conditions are considered together, $32.8 \%$ of them occur as patient delays.
In Sanliurfa, regarding the cause of patient delay, patients state reasons such as ignoring the disease or assuming that the lesion is acne. In the studies, it is also emphasized that individuals' having a low level of knowledge and awareness regarding the disease delays treatment-seeking behaviour $[11,12]$.

Although the frequency of patient delays is common in CL patients in Sanliurfa, the average stated in the India study is much lower than the value of 19.5 months and the average stated in the Bangladesh study is much lower than the value of 23.2 months. In this result, the majority of cases in India and Bangladesh had difficulty in accessing the treatment center because they lived in the countryside was effective [8, 12]. In contrast, the majority of patients in Sanliurfa live in the city center facilitates access to treatment [11, 12]. Although the mentioned results have a possible effect on treatment delay, the most important problem in patient delay in the patients in Sanliurfa seems to be the location of the lesion. Delay in non-facial lesions is 2.5 times more. Facial lesions probably cause psycho-social conditions such as anxiety, depression and social stigmatization, so they can mobilize people faster [11]. Again, in this study, it was found that the presence of two or more lesions in the patient increases the risk of delay 1.8 times. Although it is stated that polymorphic and multiple lesions are less delayed in India, the presence of multiple lesions in the extra-facial regions in this study probably leads to this result [8].

System delays are the most common cause of the treatment delays with $67.2 \%$. These delays are most commonly caused by CLDTC and secondly by dermatology clinics in public hospitals. The reason for a delay in clinics is often the inability to diagnose and wrong treatment. The system delay durations in Sanliurfa are lower than the India study (26.7 months on average) [8]. This situation is very much related to the fact that CLDTC are located in the city center and are accessible. In Bangladesh, system delay durations (1.5 months on average) are lower than in Sanliurfa. This implies that system delays can be reduced to lower levels with correct and effective interventions. The reason for the delays caused by CLDTC is the absence of medication with a maximum of $48.4 \%$. This is a center that has successfully performed diagnosis and treatment for many years. The center also conducts training and research activities. For many years, CLDTC did not cause a delay due to the absence of drugs. However, the difficulties experienced by the Ministry of Health in supplying medication during the study period caused the formation of this picture. There may be delays in two or more stages at a level of 37.2 $\%$ in system delays. The increased number of delay stages also increases the treatment delay duration. Similarly, in the Bangladesh study, applications to more than one health care center were found to delay treatment [12]. Therefore, correct referrals of patients facilitate access to treatment and reduce latency. In 
addition, the low level of patients' knowledge and awareness regarding the disease affects the early treatment-seeking behavior of the patients $[11,12]$.

\section{CONCLUSION AND DISCUSSION}

Patients' level of basic education and knowledge of the disease is low. Although the patients know that they should apply directly to the CLDTC, patient delay levels are high. The presence of lesions in regions other than the face decreases patients' behavior of seeking early treatment. Prevention of delays is one of the most important steps in CL control. Therefore, the information and awareness of the patients and the society about CL should be increased, the patients applying to CLDTC and their relatives should be informed, these training should be pursued and supported by posters and brochures in women's support centers, schools, etc.

Compliance training should be performed with appropriate time intervals in CLDTC, with dermatologist physicians, who will work in Sanliurfa to reduce system delays. Pentavalent antimony required for the CLDTC and other centers should be provided on time.

\section{REFERENCES}

1. Control of the leishmaniases. (2010). World Health Organization technical report series. (949):xii-xiii, 1-186, back cover.

2. Leishmaniasis: World Health Organization; [24.10.2018]. Available from: http://www.who.int/news-room/factsheets/detail/leishmaniasis.

3. Şark çıbanı türkiye istatistik düzeyleri: TC Sağlık Bakanlığı Halk Sağlığı Genel Müdürlüğü; 2019 [24.06.2019]. Available from: https://hsgm.saglik.gov.tr/tr/zoonotikvektorelsarkcibani/istatistik.

4. Gurel, M. S., Ulukanligil, M., \& Ozbilge, H. (2002). Cutaneous leishmaniasis in Sanliurfa: epidemiologic and clinical features of the last four years (1997-2000). International journal of dermatology, 41(1), 32-37.

5. Ok, Ü. Z., Balcığlu, İ. C., Özkan, A. T., Özensoy, S., \& Özbel, Y. (2002). Leishmaniasis in Turkey. Acta Tropica, 84(1), 43-48.

6. Neglected tropical diseases: World Health Organization; [24.10.2018]. Available from: https://www.who.int/neglected_diseases/news/Leis hmaniasis-timeline-of-facts-and-the-quest-diseasecontrol/en/.

7. Huq, K. E., Moriyama, M., Zaman, K., Chisti, M. J., Long, J., Islam, A., ... \& Rahman, M. M. (2018). Health seeking behaviour and delayed management of tuberculosis patients in rural Bangladesh. BMC infectious diseases, 18(1), 515.

8. Garapati, P., Pal, B., Siddiqui, N. A., Bimal, S., Das, P., Murti, K., \& Pandey, K. (2018). Knowledge, stigma, health seeking behaviour and its determinants among patients with post kalaazar dermal leishmaniasis, Bihar, India. PloS one, 13(9), e0203407.

9. Alvar, J., Yactayo, S., \& Bern, C. (2006). Leishmaniasis and poverty. Trends in parasitology, 22(12), 552-557.

10. Guidelines For The Treatment And Prevention Of Cutaneous Leishmaniasis In Pakistan Ministry of Health The World Health Organization Health Net International 2002 [24.10.2018]. Available from: https://www.who.int/leishmaniasis/burden/Guideli nes_for_the_treatment_and_prevention_of_CL_in _Pakistan.pdf.

11. Fernando, S. D., Siriwardana, H. V. Y. D., Guneratne, K. A. R. C. W., \& Rajapaksa, L. C. (2010). Some sociological aspects of cutaneous leishmaniasis in patients attending a tertiary referral centre in Colombo, Sri Lanka. International health, 2(1), 69-74.

12. Basher, A., Nath, P., Nabi, S. G., Selim, S., Rahman, M. F., Sutradhar, S. R., ... \& Rahman, R. (2015). A study on health seeking behaviors of patients of post-kala-azar dermal leishmaniasis. BioMed research international, 2015:314543.

13. Hanson, C. L., Osberg, M., Brown, J., Durham, G., \& Chin, D. P. (2017). Conducting patient-pathway analysis to inform programming of tuberculosis services: methods. The Journal of infectious diseases, 216(suppl_7), S679-S685.

14. López-Perea, N., Sordo, L., Gadisa, E., Cruz, I., Hailu, T., Moreno, J., ... \& Custodio, E. (2014). Knowledge, attitudes and practices related to visceral leishmaniasis in rural communities of Amhara State: a longitudinal study in northwest Ethiopia. PLoS Negl Trop Dis, 8(4), e2799.

15. Stewart, C. C., \& Brieger, W. R. (2009). Community views on cutaneous leishmaniasis in Istalif, Afghanistan: implications for treatment and prevention. International Quarterly of Community Health Education, 29(2), 123-142.

16. Gomes, A. H. S., Martines, R. B., Kanamura, C. T., Barbo, M. L. P., Iglezias, S. D., Lauletta Lindoso, J. A., \& Pereira- Chioccola, V. L. (2017). American cutaneous leishmaniasis: in situ immune response of patients with recent and late lesions. Parasite Immunology, 39(4), e12423.

17. Koruk, F. K. İ. (2018). A Neglected Group: Female Agricultural Workers. Journal of Obstetric-Women's Health and Diseases NursingSpecial Topics. 4(1):40-5.

18. Gürses, G., Dikme, R., Şimşek, Z., Muratoğlu, M., \& Yeşilova, Y. (2016). Investigation of cutaneous leishmaniasis by active screening in primary schools in Sanliurfa, Turkey. Mikrobiyoloji Bulteni, 50(4), 559-568.

19. Votýpka, J., Kasap, O. E., Volf, P., Kodym, P., \& Alten, B. (2012). Risk factors for cutaneous leishmaniasis in Cukurova region, 
Turkey. Transactions of the Royal Society of Tropical Medicine and Hygiene, 106(3), 186-190.

20. Akram, A., Khan, H. A. A., Qadir, A., \& Sabir, A. M. (2015). A cross-sectional survey of knowledge, attitude and practices related to cutaneous leishmaniasis and sand flies in Punjab, Pakistan. PloS one, 10(6), e0130929.

21. Abazid, N., Jones, C., \& Davies, C. R. (2012). Knowledge, attitudes and practices about leishmaniasis among cutaneous leishmaniasis patients in Aleppo, Syrian Arab Republic. EMHJEastern Mediterranean Health Journal, 18 (1), 7 14, 2012.

22. Sarkari, B., Qasem, A., \& Shafaf, M. R. (2014). Knowledge, attitude, and practices related to cutaneous leishmaniasis in an endemic focus of cutaneous leishmaniasis, Southern Iran. Asian Pacific Journal of Tropical Biomedicine,4(7), 566-569. 